\title{
Cross-cultural peer-mentoring: Mentor outcomes and perspectives
}

\author{
Monica L. Bellon-Harn \\ Lamar University, monica.harn@lamar.edu \\ Rebecca K. Weinbaum \\ Lamar University, rebecca.weinbaum@lamar.edu \\ DOI: doi.org/10.30707/TLCSD1.2Bellon-Harn
}

Follow this and additional works at: https://ir.library.illinoisstate.edu/tlcsd

Part of the Scholarship of Teaching and Learning Commons

\section{Recommended Citation}

Bellon-Harn, Monica L. and Weinbaum, Rebecca K. (2017) "Cross-cultural peer-mentoring: Mentor outcomes and perspectives," Teaching and Learning in Communication Sciences \& Disorders: Vol. 1: Iss. 2, Article 3.

DOI: doi.org/10.30707/TLCSD1.2Bellon-Harn

Available at: https://ir.library.illinoisstate.edu/tlcsd/vol1/iss2/3

This Scholarship of Teaching and Learning Research is brought to you for free and open access by ISU ReD: Research and eData. It has been accepted for inclusion in Teaching and Learning in Communication Sciences \& Disorders by an authorized editor of ISU ReD: Research and eData. For more information, please contact ISUReD@ilstu.edu. 


\title{
Cross-cultural peer-mentoring: Mentor outcomes and perspectives
}

\begin{abstract}
Limited relationships with peers and faculty create barriers for retaining racial or ethnic minority students through the academic path to SPHS professions. As such, university programs must pay particular attention to formalized avenues of social support to decrease attrition and increase retention (Cokley, 2000). Mentoring is one such avenue (Wright-Harp \& Cole, 2008). The purpose of this paper is to describe mentor outcomes and perspectives of a cross-cultural peer-mentoring program entitled LEAD: Leadership, Education, Advocacy, and Diversity. Graduate students from SLP and AUD graduate programs were recruited to serve as peer mentors to potential undergraduate candidates representing diverse ethnicities who might be interested in a career in SLP or AUD. Using a qualitative-dominant concurrent mixed method design, goals, values, and barriers as well as differences in cultural constructs perceived by graduate students as a result of participating in LEAD are examined. Outcomes and future direction of the peermentoring program are discussed.
\end{abstract}

\section{Keywords}

Peer-mentoring, diversity, retention

\section{Cover Page Footnote}

This program was funded by the Texas Higher Education Coordinating Board: Minority Health Research and Education Grant Program. 


\section{Introduction}

For more than two decades, leaders and policy makers in higher education have focused on the educational gaps that exist for minority populations, especially at the graduate student level (American Council on Education, 2011). Likewise, professionals and graduate students from diverse backgrounds in the field of communication sciences and disorders (CSD) are significantly underprepresented (American Speech-Language-Hearing Association [ASHA], 2016a; 2016b). The absence of representation across all racial and ethnic minority groups limits the ability of the CSD profession to meet the needs of diverse cultures and adds to the problem of health disparities as a whole (Wright-Harp, Mayo, Martinez, Payne, \& Lemmon, 2012). Further, lack of diversity limits perspectives of professionals who work with different populations and hinders the ability to generate creative and innovative ideas (ASHA, n.d.). To increase the diversity of CSD professionals, university leaders of college programs must recognize new strategies for attracting, retaining, and graduating CSD students from diverse backgrounds (Stewart \& Gonzalez, 2002). Recognizing the barriers that hinder individuals from racial and ethnic minority groups from pursuing graduate work is the first step.

\section{Barrier to CSD professions: Social support}

If students perceive limited support to participating in graduate CSD programs, students may not be successful despite interest or ability. In particular, social supports are critical for success of students from diverse groups (Saenz, Wyatt, \& Reinard, 1998). Solberg and Viliarreal (1997) reported that Hispanic college students who perceived strong social support had less stress and higher selfefficacy. Phinney, Dennis, and Chuateco (2005) reported that peer support is a positive predictor of improved GPA in students from ethnic minority groups. Unfortunately, students from diverse groups have less interaction with faculty and peers, which can create a climate of social isolation (Wong, Seago, Keane, \& Grumbach, 2008). A feeling of disconnection may be compounded by a lack of representation in faculty and peers (Lent, Hackett, \& Brown, 1999). Differential socialization experiences and needs result in low academic self-efficacy and subsequent poor academic performance (Gloria \& Hird, 1999). These barriers may discourage students from continuing on the path to the profession in CSD (Kohnert, 2013; Wright-Harp \& Cole, 2008).

\section{Social support through peer-mentoring}

University programs must pay attention to formalized avenues of social support to decrease attrition and increase retention (Cokley, 2000). Mentoring is one such 
avenue (Wright-Harp \& Cole, 2008). Students from racial and ethnic minority groups who have opportunities for mentoring are more likely to persist in a CSD graduate program than those that do not (Saenz, 2000). Some mentoring program models describe strategies to support graduate students in CSD programs. Of those, Wright-Harp and Cole (2008) recommended multiple mentors, including peers, as students matriculate through graduate school. The authors suggested that peer mentors could motivate their mentees and provide professional guidance. In turn, peer mentors may develop leadership skills. Wright-Harp and Muñoz (2000) highlighted active engagement of graduate students in peer advising relationships as a retention strategy for preparing graduate students as bilingual speech-language pathologists. The authors described the mentor role as helping new students on campus, leading study groups, and helping mentees develop professional behavior. Rentschler and Gasior (2011) described a peer mentoring program for clinical training in speech-language pathology (SLP) and reported mutual benefit for both the graduate student mentor and mentees. In particular, the mentor felt that she developed confidence and perspective on the clinical process.

\section{Best practice components of peer-mentoring}

Historically, mentoring programs represent effective learning relationships across various disciplines. Mentoring, at its best, is a synergestic process that links diverse perspectives "as a psycho-social endeavor by individuals working together to create a greater good for both mentors and mentees" (Irby, 2012; p. 175). Much dialogue has centered upon school-based mentoring, which is defined as a supervised experience between a mentor (one with experience) and a mentee (one with less experience) on a K-12 campus setting (Karcher \& Herrera, 2008). Models for mentoring in a school-based setting underscore the relational aspect of trust as the single-most characteristic for success (Bennetts, 2003). Strong structure and system supports, such as training, articulated goals, space, and resources, are critical as well (Karcher, Kupernminc, Portwood, Sipe, \& Taylor, 2006). Further, Shelmerdine and Louw (2008) suggest that school-based mentoring requires help, knowledge, and friendships. To address the latter, Keller and Pryce (2010) suggest that mentors can diminish some of the power differences that might be inherent between a mentor and a mentee. In school-based mentoring, successful factors include authenticity, empathy, collaboration, and companionship (Spencer, 2006; 2007). Lack of motivation, unfulfilled expectations, poor relational skills, family interference, and inadequate program support may result in unsuccessful mentoring (Spencer, 2006; 2007). Peer mentoring is one approach that creates a context for many of these best practice components (cf. Karcher, 2005; Randolph \& Johnson, 2008; Rhodes \& DuBois, 2008) that can be translated into mentoring relationships at the college level. 


\section{Cross-cultural mentoring characteristics}

Kochan, Searby, George, and Edge (2015) reported on the effects of a college-level course and the cultural aspects of mentoring. These researchers identified cultural barriers in mentoring, one of which addressed the collective climate of the organization or community as being closed-minded to outside ideas and static in habits of judging others. One solution put forth by Kochan et al. (2015) for speaking to the cultural barriers was to provide mentors with training for how to address social and cultural differences. Similarly, Sufrin (2014) defined the role of multicultural competence for predicting positive mentor change and overall satisfaction. Multicultural competence was contingent on mentors having the ability to understand their biases and personal backgrounds and the concept of privilege, which should be addressed for a mentoring team in formalized training that includes opportunities to converse about sensitive topics (Sufrin, 2014).

While much literature exists to identify cross-cultural mentoring effectiveness in school-based settings (Dubois \& Rhodes, 2006; DuBois, Portillo, Rhodes, Silverthorn, \& Valentine, 2011; Frels \& Onwuegbuzie, 2012; Frels, et al., 2013), cross-cultural peer mentoring programs in a college setting are in the early stages of development with mixed results (Budge, 2006). Plaut, Thomas, and Goren (2009) revealed that if institutions are to address lasting effects for minority representation a focus on increasing numbers is not enough. In fact, Plaut et al. (2009) demonstrated that a positive climate for diversity is the highest contributing factor for substantially increasing minority representation. A focus only on increasing numbers for minority representation may in fact be detrimental in this effort (Plaut et al., 2009).

\section{LEAD cross-cultural peer-mentoring program}

Peer-mentoring at the college level has developed as a well-established strategy for student retention in health care fields such as CSD (Gilchrist \& Rector, 2007). However, few reports describe CSD peer-mentoring programs dedicated to retention of undergraduate students on the path toward graduate education. The first and second author created a cross-cultural peer-mentoring program entitled LEAD: Leadership, Education, Advocacy, and Diversity. LEAD was designed as an intersect between the goal to increase the numbers of students from racial and ethnic minority groups and the building of a positive cultural climate (Plaut, 2010). Graduate students from a master's degree programs in SLP or a clinical doctoral program of audiology (AUD) were recruited to serve as peer mentors. 
Mentees included undergraduate students who were recruited after attending a brief seminar about the institution's CSD programs and LEAD peer-mentoring.

A major focus for establishing LEAD was to minimize aspects of power (e.g., social, gender) and permanence (i.e., the degree to which a relationship is stable as a type of kinship) as described by Keller and Pryce (2010) for cross-cultural mentoring. The theoretical framework for understanding the training, implementation, and evaluation of LEAD was social cognitive theory (Banadura, 1997; Bandura \& Locke, 2003). Both the mentors and the mentees experience change through observed behaviors, values, beliefs, and attitudes shared in a dyadic exchange. In addition, social cognitive theory situates motivation for learning with four interconnected components: (a) meaning-making in both an individual and collective process; (b) practice, use of shared social resources, history, and perspectives; (c) community - social structures and what is worth pursuing; and (d) identity - learning that results from the mentoring dyad in a community context (Bandura, 1997).

The current research was part of a larger study which focused on recruitment and retention of students from racial and ethnic minority groups. The purpose of the current study was to identify and evaluate mentors' experiences in LEAD with respect to goals, values, challenges, and program components. A secondary purpose was to evaluate the impact of LEAD on mentors' cultural competence and any collective changes in the CSD program's learning environment. Using a qualitative-dominant concurrent mixed methods design (i.e., both quantitative and qualitative data were collected at the same times throughout the study), research questions were as follows:

\section{Qualitative research questions:}

What are the goals and values of graduate student LEAD mentors relating to culture and diversity?

What are the barriers to successful cross-cultural mentoring perceived by graduate student LEAD mentors?

\section{Quantitative research question:}

What differences exist in cultural constructs of graduate student LEAD mentors as a result of participating in LEAD?

\section{Mixed methods research question:}

What is the impact of LEAD on attitudes of graduate students and overall program learning environment? 


\section{Methodology}

A mixed methods design was selected to address complementarity, which means the intent to measure overlapping facets of a phenomenon (Greene, Caracelli, \& Graham, 1989). As a qualitative dominant mixed methods study, the intent for including a quantitative aspect was to situate the qualitative findings with normative data (Frels \& Onwuegbuzie, 2013). In addition, we sought to increase the validity of our interpretations that stemmed from the qualitative inquiry.

Participants and setting. Thirty CSD graduate students participated as mentors in LEAD across the course of two years (15 graduate students per year). The graduate students mentored undergraduate students interested in the field of CSD or majoring in a CSD undergraduate program. During Year 1, 10 mentors were identified as White, three were identified as African American, and one mentor was identified as Hispanic. One of the mentors was a male student and the other mentors were female. During Year 2, nine mentors were identified as White, two mentors were African American, and three mentors were Hispanic. Two of the mentors were male students and the other mentors were female. After mentor selection, each mentor signed a letter of commitment. The study took place on at Lamar University, which is located in the southeast region of Texas.

Instruments and procedures. The first author conducted the interviews for selecting LEAD mentors. Selection was based on their interest in LEAD and a subsequent interview. Appendix A presents the question set and associated rubric for selecting mentors.

The second author, who was trained as a professional counselor, facilitated the mentor training and group support component for a period of six months in Year 1. Training consisted of targeted lessons on cultural, social, and political attributes related to the disparities in the CSD field. During the first six months of Year 2, training consisted of weekly mentor support groups, which were facilitated by a graduate student in the counseling program at the same university. Activities within the weekly meetings included open group discussions about what did and did not work in the mentoring process. An online course management system was used to post additional training activities. The guided training activities included: (a) selected readings (e.g., Kohnert, 2013; Ebert, 2013); (b) a series of leading questions to help students understand their worldview, consider their identities, and identify personal barriers; and (c) personal stories told from various cultural viewpoints (e.g., Storycorps interviews https://storycorps.org). Both Year 1 and 2 included a mentor task force in areas of outreach (e.g., maintaining a facebook page, 
tutoring, career activities, public awareness activities, bilingual material development).

Qualitative data. Artifact data included reflective journal entries and focus group transcripts. These were designed as formative program measures for mentors. Reflective journal entries were evaluated as they related to the main goals of LEAD (i.e., mentoring processes; cultural processes). These entries were completed immediately after group meetings or group discussions and submitted electronically.

In addition, focus group interviews were conducted with all LEAD mentors at midpoint in the academic year and at the conclusion of the academic year. Focus groups consisted of three groups representing four to six members each, depending on the LEAD mentors' availability. According to Morgan (1997) three focus groups are sufficient for addressing saturation, informational redundancy, and theoretical saturation. The focus groups were semi-structured interviews conducted by the second author and an undergraduate student in counseling. The two interviewers were selected to expand perspective and navigate through any power aspects that might have been present. The focus group interview questions were created to launch discussions relating to mentors' behaviors, values, beliefs, and attitudes aligned with social cognitive theory (Banadura, 1997; Bandura \& Locke, 2003) and perceptions of the program over the 2-year program span (See Appendix B).

Quantitative data. In addition to the qualitative data, quantitative data were collected via The Inventory for Assessing the Process of Cultural Competence in Mentoring (IAPCC-M; Campinha-Bacote, 2008) to assess cultural competence of mentors. The IAPCC-M was completed pre- and post-mentor training. The IAPCC$\mathrm{M}$ is a reliable self-assessment tool consisting of nine items that measure the five cultural constructs of cultural desire, cultural awareness, cultural knowledge, cultural skill and cultural encounters as it relates to the mentoring process (Greenberg, 2013; Gibbs \& Culleiton, 2016). Scores range from 9 - 36 and indicate whether a mentor is operating at a level of cultural proficiency, cultural competence, cultural awareness or cultural incompetence in their mentoring relationships. Higher scores depict a higher level of cultural competence in mentoring. The IAPCC-M uses a 4-point Likert scale reflecting the response categories of strongly agree, agree, disagree and strongly disagree. Scores between 9-18 were considered culturally incompetent, 19-28 were considered culturally aware, 29-33 were considered culturally competent, and 34-36 were considered culturally proficient. The tool was designed for faculty members; however, the items referred generally to the mentoring process. As such, the tool was used with permission from its developer. 
Data analyses. To analyze the qualitative data, Charmaz's (2012) format used in grounded theory via constant comparative analysis (Glaser \& Strauss, 1967) was implemented. Categories, properties, desciptions, and interpretations were focused toward increasing understanding of cross-cultural peer mentoring. First, the nine items from the IAPCC-M were used to create initial codes for focus group transcripts. In addition, reflective journal entries were coded and categorized via open and selective coding. Line-by-line open coding (Strauss \& Corbin, 1990) and qualitative data analysis software (QDAS), specifically QDA Miner (Provalis Research, 2011) was utilized to build schemes and theoretical concepts during the analysis phase of the study.

As explained by Charmaz (2012), grounded theory coding involves two main phases: (a) initial phase, which is coding by word, line, or segment; and (b) focused phase, which involves selecting the most significant or frequent initial codes. In the focused phase, constant comparison analysis (Strauss \& Corbin, 1990) was the means for sorting, categorizing, and focusing the codes into meaningful themes. Next, data were analyzed using axial coding, which led to developing the major categories specific to the perceived goals and values of LEAD mentors. Emerging categories were compared and contrasted using theoretical coding, which resulted in broader schemes relating to consequences and/or barriers perceived by mentors. When no new codes and/or categories emerged, it was determined that saturation was reached. Criteria for core concepts were: (a) the concept was central to all categories; (b) the concept was frequent within all categories; (c) the concept had implications for a more general theory; and (d) the category allowed for variation with respect to conditions, consequences, and strategies (Strauss \& Corbin, 1990).

The first stage/layer of data analysis involved an independent coder who was an undergraduate student assistant working with the authors. Inter-coder agreement in the first stage/layer of coding resulted in $90 \%$ reliability. In the second and subsequent stages/layers, larger thematic concepts and schemes were identified using discussions and consensus to seek implicit meanings, actions for new directions, and emergent links to other concepts (Glaser \& Strauss, 1967). Next, the authors scrutinized categories to understand patterns and situated the findings with descriptive cultural competence results from the quantitative instrument IAPCC-M (Campinha-Bacote, 2008). As a final step for integrating the layers of data analysis, the authors solicited a third and independent reviewer of data, similar to the use of an auditor in the tradition of consensual qualitative research (Hill, Thompson, \& Williams, 1997). As such, understanding of the qualitative analysis through the lens of the quantitative analysis was expanded for overall core ideas. 
To analyze the quantitative data, pre- and post-test results of the IAPCC-M were compared using the Wilcoxon test due to the small number of participants and scaling of the cultural competence measurement tool.

\section{Results}

\section{Goals and values of LEAD mentors}

Year 1.To determine goals and values of first-year mentors, a total of 387 statements from 15 mentors were analyzed. Seventy-eight percent of the statements were related to mentor processes. Twenty-two percent were related to cultural processes. Three major themes emerged: (a) mentor processes with a focus on self, (b) mentor processes with a focus on the mentee relationship, and (c) cultural processes relating to mentoring. In Year 1 the majority of LEAD mentors were concerned with the role they played and if they were perceived as helpful or appreciated.

Associated with the theme mentor processes (mentor focus) were three subthemes: (a) effectiveness, or the feeling of being helpful to the mentee; (b) teamwork, or the ability to work with other mentors to impact the overall LEAD outreach; and (c) personal growth, or the values associated with improved skills and relationships. For example, the subtheme effectiveness was expressed by a mentor to be focused on the profession (e.g., "I cannot wait to share my story with mentees and really show them what our profession is all about and what makes it special."). Thirteen of the mentors expressed similar ideas related to effectiveness. The subtheme teamwork was identified by three of the mentors. One expressed the following:

During the course of my time in the program I have been able to see myself grow in the aspects of trusting others to do their work in a group work situation. Before this program I relied on myself to make sure others did their part, while in this group I have learned to truly trust others. I also have learned that it is ok to not know the answers to all the questions, I learned that when you ask questions that makes you more relatable to your peers and mentees.

The subtheme personal growth was identified by eleven mentors as a goal in the area of discovering personal qualities through working with mentees on tasks related to the profession and the CSD Department. For example, one mentor reflected, "In my private life, I would like to learn how to listen better and not just jump into fixing things." 
Mentor processes (mentee focus) were identified as a second, yet less discussed goal for LEAD Mentors. This theme was defined by instances that a mentor recognized the unique story of the mentee relating to societal barriers or personal struggles. In this theme, two subthemes emerged. The professional relationship development subtheme was defined as a heavy emphasis on relational elements for their mentees such as communications with instructors, navigating personal struggles, and other supports. The other subtheme, facilitating mentee knowledge/skills, was defined provision of direct information for supporting coursework, leadership, and steps for applying to the graduate program. Relating to the subtheme of professional relationship development, one mentor described the goal for a master's level education through the lens of her mentee:

A lot of the problems my mentee faces is rooted in the fact that she is the first in her family to try to go to grad school. It is very competitive to get into graduate school for speech pathology. Last year, [our program] had over 300 applicants for only 30 spots. It is difficult to learn how to deal with the stress and the constant pressure to make all As.

Seven of the mentors expressed ideas related to professional relationship development. In the subtheme of facilitating mentee knowledge/skills, mentors expressed, "We're building relationships constantly" and "I made her a packet that outlined the requirements and everything that she had to do. I just downloaded it from ASHA and put it in a folder and had it for her." Eight mentors valued the inclusion of their mentees in CSD program activities as a means to facilitate their mentee's knowledge and skills. One mentor reported, "We had a tutoring group, the workshop for writing as well, and the career day. My mentee said those were helpful."

The theme cultural processes was the final area of values and goals, with three subthemes (a) awareness, (b) common ground, and (c) discussion and discomfort. Four of the fifteen mentees expressed the subtheme of awareness. One explained:

I'm thankful for all of the different points we have discussed today. It is very different to be in a room full of people that I barely know, who all come from different walks of life. Talking about race, mentoring, our influences...very inspiring and eye opening.

The subtheme common ground was revealed through four of the mentors. One mentor stated that "life is so simple but complicated due to our feelings, characteristics, and what we believe in. Regardless of your make-up you are human and you have your own personal way of living your life." 
The majority (11 of 15) of mentors in Year 1 expressed the subtheme of discussion and discomfort, which was revealed by communications seeking to avoid the discussion of culture and/or diversity such that "the conversation [of priviledge] was difficult to have but needed" and "I felt uncomfortable when talking about race." (See Appendix C for additional examples of the Year 1 themes).

Year 2. With regard to reflective journal data, a total of 345 statements were analyzed. As with Year 1, the majority of statements were related to the mentor process (i.e., 63\%) rather than cultural processes (i.e., 37\%). However, the frequency of comments related to cultural processes was greater in Year 2 than Year 1. Additionally, the themes of mentor processes (mentor focus), mentor processes (mentee focus), and cultural processes shifted emphasis in Year 2 mentors. Associated with mentor processes (mentor focus) three sub-themes emerged. These included (a) open to experience, (b) personal growth, and (c) teamwork. All Year 2 mentors appeared to be open to the mentoring experience and relationships with mentees. For example, one mentor commented, "We were able to open our mind to other opinions and even we didn't agree necessarily we accepted them and respected them." Year 2 mentors reflected a sense of value for knowing oneself, especially with a sense of honor and commitment for continued work in the area of cultural awareness. For example, one mentor wrote, "I really like being part of this program-it's making me look at myself, how I relate to others, and how I feel about myself and the work I'm doing." Overall, six of the mentors discussed personal growth. While the subtheme of teamwork was present in both mentor groups, Year 2 mentors wrote about teamwork with greater frequency and all Year 2 mentors commented on teamwork. Further, within the subtheme of teamwork, support as a crucial component was written and discussed with greater frequency in Year 2 than Year 1. For example, one mentor noted, "These activities are bringing us all closer together and I feel as though we are all working to build each other up as well as our mentees." Another reported, "I think everyone's personality is uniquely suited to make this experience a great one for them and their mentees."

With regard to mentor processes (mentee focus), four subthemes emerged. These included (a) open to relationship, (b) goal setting, (c) concern for mentee knowledge/skills, and (d) professional and personal relationships. All Year 2 mentors described an openness to the relationship. Seven of the Year 2 mentors wrote about specific goals for their mentees, which was not present in Year 1 mentors. For example, rather than focus on a sense of feeling helpful, which was an emphasis in Year 1 mentors, Year 2 mentors established a more open stance to specific tasks such as, "I now know that my goal is to get them involved in the 
profession and provide resources to help alleviate stress about graduate school." Additionally, all mentors included comments related to the development of friendship (i.e., professional and personal relationships subtheme) with mentees. One Year 2 mentor remarked, "I really think she just wants a friend, and I will definitely be her friend and listen." Another Year 2 mentor reported, "We had a small mentor-mentee hang out on Thursday. That was really nice to get to know everyone and just hang out in a non-school environment."

Year 2 mentors exhibited a focus on a collective mentorship effort and activities and goals for mentees (e.g., I think that's why it's important for me to really come up with meaningful activities that are going to interest my mentees and make a difference). As with Year 1, Year 2 mentors valued CSD program activities as a means to facilitate their mentee's knowledge and skills (e.g., concern for mentee knowledge/skills subtheme). For example, one mentor reported that she, "emailed her about some more opportunities for her (NSSLHA and university-wide activities) and she wrote back that the information was exactly what she needed, so I am glad that I could help her out." As a group, all mentors included comments related to concerns for mentee knowledge and skills.

Subthemes related to cultural processes included (a) openness, (b) discussion and growth, and (c) empathy. Unlike Year 1, the themes from Year 2 did not include discomfort or concern related to cultural processes. Rather Year 2 mentors found many opportunities to discover new insights. For example, one mentor shared that "Even this seemingly simple difference in culture was a great learning experience for both of us." Eight of the mentors described ideas related to openness and nine of the mentors referred to opportunites for discussion and growth. In particular, the subtheme of empathy, rather than competence, within cultural processes was highlighted by six of the mentors. The following statement exemplifies this theme: "I gave her some idea of my background and where I come from and also what I hope to help her with. She, in turn, told me the same." (See Appendix D for additional examples of Year 2 themes).

\section{Barriers to successful cross-cultural mentoring perceived by LEAD mentors}

Year 1. Mentors identified structural and relationship barriers in reflective journals and focus group discussions. One structural barrier included scheduling time with mentees. One mentor stated, "We did have a difference in our schedules, so she was only here on campus on Tuesdays and Thursdays." Another stated, "I think that was the hardest part this semester. We were so busy with grad school. It sometimes slipped my mind to even check on my mentee." In sum, challenges arose due to due to work, school, and family schedules. A second structural barrier included location. One mentor stated, 
She went to school at Lamar in the Fall and then in the Spring she moved home to Houston because there were no classes she could take specific to Lamar, so she went back home to save money. But she still made her way down here to observe me.

Many mentees were community college students completing their associate of science or arts degree prior to transferring to Lamar University. As such, they were not on-campus and the mentors experienced challenges finding meeting locations.

Relationship barriers included mentor perceptions that mentees lacked motivation. One mentor stated, "I always had to contact mine. She doesn't try to contact me." This was echoed in another statement, "Did they ever think to check up on their mentor?" Another wrote, "I was surprised I guess by the lack of responsiveness by my mentee." Consequently, mentors experienced unfulfilled expectations at times. Several mentors felt that more program support was needed in that the mentors wanted explicit guidelines and requirements for themselves as well as their mentees. This was evidence in specific feedback (i.e., I think more structure would have helped.) On the other hand, some mentors preferred the flexibility and provided their own structure. For example, one mentor reported, "With ours, I felt like things were pretty structured. We had a set time, we had what we wanted to talk about once we got there."

Another wrote,

Having it being structured, as far as knowing what goals you have in mind, and what objectives you want to accomplish, but having it be free enough, or less structured enough, for us to be open and bounce ideas off of one another.

Year 2. Mentors highlighted time and location challenges. However, these were identified as potential challenges rather than barriers to mentoring processes. No additional barriers were noted for Year 2.

\section{Differences in cultural constructs of LEAD mentors}

Year 1 mentor responses on the IAPCC-M were not significantly different $(z=-$ $1.93 ; \mathrm{p}=.053)$. Pretest scores $(M=27.61 ; S D=3.73)$ indicated that mentors felt that they were culturally aware prior to the LEAD program. Posttest scores $(M=29.92$; $S D=3.61$ ) indicated that mentors felt that they were culturally competent. Pre-post comparison of Year 2 responses resulted in significant differences $(z=-3.30 ; \mathrm{p}=$ $.001)$. Pretest scores $(M=25.64 ; \mathrm{SD}=4.16)$ indicated that mentors felt they were 
culturally aware prior to the LEAD program. Posttest scores $(M=31.64 ; \mathrm{SD}=3.81)$ indicated that mentors believed that they were culturally competent. Year 1 and Year 2 gains from pre- and post-survey responses were compared. Significant differences were noted $(z=-2.49 ; \mathrm{p}=.013)$. The mean gain from Year 1 reponses was 2.7 points $(S D=4.11)$ and the mean gain from Year 2 responses was 6 points $(S D=2.54)$. Both groups increased their perceptions of their level of cultural competence. However, the changes during Year 2 were stronger.

\section{Impact of LEAD on attitudes of graduate students and program climate}

Several changes to the mentor training component prior to the initiation of the second year occurred. Specific reflection prompts to increase open discussion regarding cultural encounters with culturally/ethnically diverse mentees and/or disadvantaged mentees were included for two reasons. First, Year 1 mentors discussed the mentoring processes a majority of the time rather than cultural processes. Second, discomfort during discussions simultaneous with the desire for more discussion. Activities targeting knowledge of potential barriers and strategies within mentoring processes were increased because mentors reported concerns related to motivation of mentees and their unfulfilled expections. These new components increased the structure of the program and explicated goals of the program, which was identified as a need. Consequently, attitudes shifted from Year 1 to Year 2. Overall, LEAD Mentoring impacted the graduate students' attitudes toward themselves and their mentees. The program created a climate for open discussion and consideration of mentoring and cultural processes.

\section{Discussion}

This investigation sought to explore and identify mentors' goals, values, challenges, and perceptions of a cross-cultural peer mentoring program designed to address diversity of students in CSD professions. Successful cross-cultural mentoring requires authentic companionship and friendship (Spencer, 2006; 2007). Development of friendship is predicated by equality, which is present in peer mentoring contexts. Year 1 and Year 2 mentors perceived value for alliances with mentees and with each other. A focus on friendship and connectedness occurred with greater frequency in Year 2 than in Year 1. As noted by Keller and Pryce (2010), decreasing a sense of power between mentees and mentors helps to facilitate signicant friendship. Targeted activities for LEAD mentors in Year 2, built on findings related to Year 1, included explicit discussion of biases, personal backgrounds, and concepts related to privilege and power. These focused activities potentially increased Year 2 LEAD mentors' openness to deeper relationships. 
Other successful factors of LEAD aligned with Shelmerdine and Louw's (2008) concepts of help and knowledge in cross- cultural mentoring. Year 1 and 2 LEAD mentors echoed these values. Mentors prioritized community outreach goals and enjoyed including their mentees in departmental activities. Academic supports such as workshops on interviewing, formal email writing, resume writing, and GRE preparation as well as tutoring opportunities for core major couses such as phonetics were identified as successful and necessary components for LEAD. Opportunities to learn about on-campus supports such as the writing center and library were highlighted. Overall, mentors developed friendships, albeit with greater strength in Year 2, through engagment in general socialization activities (e.g., building homecoming float, pizza social).

It was apparent that the cross-cultural mentoring program endured growing pains. During the initial year of LEAD, mentors identified lack of mentee's motivation, unfulfilled expectations, and inadequate program support as barriers. As noted, necessary components of mentoring programs include strong structure and system support (Karcher et al., 2006). Some Year 1 mentors reported a need for greater structure, while others enjoyed the flexibility. Therefore in Year 2, it was important for the program structure and goals of LEAD to be explicated in greater detail. Year 2 mentors did not include any comments related to the structure, suggesting a level of comfort with the structure and system support. Instead, comments were related to the mentoring relationships and processes both with mentees and other mentors. Year 1 mentors perceived that mentees lacked motivation, which contributed to unfulfilled expectations. As part of program adjustments, support and greater collaboration among mentors was targeted in Year 2 goals. Clearly, as noted by Spencer (2006, 2007), the increased collaboration and teamwork promoted increased perceived value among LEAD mentors for understanding benefits of working with a mentee from a different background.

Location and time were identified as barriers by Year 1 LEAD mentors. While this did not change in Year 2, solutions related to use of social media were highlighted. In fact, location and time issues were reported as challenges, not barriers in Year 2. Mentors perceived that time and location barriers could be easily overcome with an emphasis on social media. For example, Facebook pages for both mentors and mentees that highlight on and off campus events for the group were identified as effective.

Overall, findings from this study corroborate reports from Wright-Harp and Cole (2008), Wright-Harp and Muñoz (2000), and Rentschler and Gasior (2011) that mentors benefit from the mentoring relationship. The LEAD mentors in the current study reported strides in both personal growth and development as well as 
enthusiasm for the profession as a whole. In fact, the use of empathy as an additive component for Year 2 mentoring indicated that the benefits for mentors moved into a surprisingly new direction.

\section{Implications for cross-cultural CSD mentoring programs}

Outcomes of this study point toward several considerations for successful efforts in recruiting and retaining underrepresented populations for diversity. First, include peer-mentoring as a focal component for continual program improvement. As noted in CSD mentoring programs at the graduate level, peer-mentoring is a recommended component in that it integrates a relational focus on program inputs. Outcomes of this investigation highlight cross-cultural peer mentoring as a viable option for focusing all players-graduate students and university program directors - toward the efforts for increasing retention of underrepresented populations in the field of CSD and SLP/AUD programs. Second, initiate crosscultural mentoring programs with strong structure and system support. It may be that graduate students in CSD have varying levels of background knowledge in mentoring processes, and especially in mentoring diverse populations. As such, strong structure may decrease anxiety about the program so mentors can focus on building relationship, teams, and community. Third, as noted by Kochan et al. (2015), addressing cultural barriers requires explicit training on how to initiate difficult converstions and recognize social cultural differences. Explicit activities can provide open discussions so that, as noted by Sufrin (2014), peer mentors better develop the ability to understand their biases and backgrounds. As modeled through the current study, collaborations between faculty in CSD and a counseling department can be benefitial for increasing support and vision for cross-cultural mentor programs.

\section{Limitations}

LEAD mentor trainings were only documented and measured through attitudinal data, specifically the self-reported inventory on cultural competence via the IAPCC-M and reflective journals. An observation protocol documenting social and/or behavioral outcomes of LEAD mentors would have augmented the attitudinal data. Additionally, it is important to note that the guiding theoretical framework for this study related to notions of power and kinship (Keller \& Pryce, 2010). Limitations of this study are directly related to how graduate students might perceive their positions as students working with faculty. The context of a university setting diminishes the possibility to completely minimize the power dynamics inherent in higher education and graduate student culture. 


\section{Future Explorations}

As noted, the current study was part of a larger effort to establish the structures necessary to increase minority representation in the CSD program at one university. Although the purpose of the current study did not address overall mentee outcomes, it is our plan to continue efforts to understanding the impact of cross-cultural mentoring from the mentee perspective, including mentee self-efficacy as a result of LEAD mentoring, perceptions and values of LEAD mentoring, and numbers of mentees applying to and enrolling in SLP or AUD graduate programs. This line of inquiry will contribute to understanding the issue of recruitment and retention of diverse populations in CSD programs.

Additionally, the current study provides a potential road map for building the foundational elements for effective cross-cultural mentoring trainings in health care professions. In particular, future directions could include specifying frequency and types of activities as well as issues surrounding the role of empathy. Future research might expand on values and goals of mentors that relate to cross-cultural mentoring to explore institutional or other barriers. As we experienced changes in overall program climate and graduate student mentor attitudes, it came to the fore that longterm measures should be in place to recognize if LEAD mentors continue their efforts to create personal relationships with potential and/or novice professionals from underrepresented populations.

\section{Acknowledgement}

This work was supported in whole or in part by a grant from the Texas Higher Education Coordinating Board (THECB). The opinions and conclusions expressed in this document are those of the authors and do not necessarily represent the opinions or policy of the THECB. The authors would like to thank Dr. Bill Ogletree for his thoughtful evaluation of the focus group transcripts and journal entries.

\section{References}

American Council on Education. (2011). Minorities in higher education. Retrieved from http://diversity.ucsc.edu/resources/images/ace_report.pdf

American Speech-Language-Hearing Association (n.d.) Exemplary Practices in Recruitment, Retention and Career Transition of Racial/Ethnic Minorities to Communication Science Disorders (CSD). Retrieved from http://www.asha.org/practice/multicultural/recruit/exemplarypractices/

American Speech- Language- Hearing Association. (2016a). ASHA summary membership and affiliation counts, year- end 2015. Retrieved from 
http://www.asha.org/uploadedFiles/2015-Member-

Counts.pdf\#search $=\% 22$ highlights $\% 22$

American Speech-Language- Hearing Association. (2016b). Communication Sciences and Disorders (CSD) Education Survey National Aggregate Data Report: 2014-2015 academic year. Retrieved from www.asha.org.

Bandura, A. (1997). Self-Efficacy: The exercise of control. New York, NY: W. H. Freeman.

Bandura, A., \& Locke, E. A. (2003). Negative self-efficacy and goal effects revisited. Journal of Applied Psychology, 88(1), 87-89.

Bellon-Harn, M. \& Weinbaum, R. (2015). LEAD: Leadership, Education, Advocacy, and Diversity. Unpublished program.

Bennetts, C. (2003). Mentoring youth: trend and tradition. British Journal of Guidance and Counseling, 31(1), 63-76.

Budge, S. (2006). Peer mentoring in postsecondary education: Implications for research and practice. Journal of College Reading and Learning, 37(1), 7185.

Campinha-Bacote, J. (2008). Assessing the Process of Cultural Competence in Mentoring. Blue Ash, OH: Transcultural C.A.R.E. Associates.

Charmaz, K. (2012). Constructing Grounded Theory (2nd ed.). Thousand Oaks, CA: Sage.

Cokley, K. (2000). An investigation of academic self-concept and its relationship to academic achievement in African American college students. Journal of Black Psychology, 26(2), 148-164.

DuBois, D. L., \& Rhodes, J. E. (2006). Introduction to the special issue: Youth mentoring: Bridging science with practice. Journal of Community Psychology, 34(6), 647-655.

DuBois, D. L., Portillo, N., Rhodes, J. E., Silverthorn, N., \& Valentine, J. C. (2011). How effective are mentoring programs for youth? A systematic assessment of the evidence. Psychological Science in the Public Interest, 12(2), 57-91.

Ebert, K. D. (2013). Perceptions of racial privilege in prospective speech-language pathologists and audiologists. SIG 14 Perspectives on Communication Disorders and Sciences in Culturally and Linguistically Diverse (CLD) Populations, 20(2), 60-71.

Frels, R. K., \& Onwuegbuzie, A. J. (2012). The experiences of selected mentors: A cross-cultural examination of the dyadic relationship in school-based mentoring. Mentoring \& Tutoring: Partnership in Learning, 20(2), 1-26.

Frels, R. K., \& Onwuegbuzie, A. J. (2013). Administering quantitative instruments with qualitative interviews: A mixed research approach. Journal of Counseling \& Development, 91(2), 84-194.

Frels, R. K. , \& Onwuegbuzie, A. J., Bustamante, R., Garza, Y., Leggett, E., Nelson, J. , \& Nichter, M. (2013). The purposes and approaches of selected mentors 
in school-based mentoring: A collective case study. Psychology in the Schools, 50(6). 1-14.

Gibbs, D. K., \& Culleiton, A. L. (2016). A project to increase educator cultural competence in mentoring at-risk nursing students. Teaching and Learning in Nursing, 11(3), 118-125.

Gilchrist, K. L., \& Rector, C. (2007). Can you keep them? Strategies to attract and retain nursing students from diverse populations: Best practices in nursing education. Journal of Transcultural Nursing, 18(3), 277-285.

Glaser, B. G., \& Strauss, A. L. (1967). The discovery of grounded theory: strategies for qualitative research. Chicago, IL: Aldine.

Gloria, A. M., \& Hird, J. S. (1999). Influences of ethnic and nonethnic variables on the career decision- making self- efficacy of college students. The Career Development Quarterly, 48(2), 157-174.

Greene, J. C., Caracelli, V. J., \& Graham, W. F. (1989). Toward a conceptual framework for mixed-method evaluation designs. Educational Evaluation and Policy Analysis, 11(3), 255-274.

Greenberg, N. E. (2013). A project to increase faculty's cultural competence in mentoring English as a second language nursing students. Teaching and Learning in Nursing, 8(4), 128-135.

Hill, C. E., Thompson, B. J., \& Williams, E. N. (1997). A guide to conducting consensual qualitative research. The counseling psychologist, 25(4), 517572.

Irby, B. J. (2012). Editor's Overview: From mentoring synergy to synergistic mentoring. Mentoring \& Tutoring: Partnership in Learning, 20(2), 175179.

Karcher, M. J. (2005). The effects of developmental mentoring and high school mentors' attendance on their younger mentees' self-esteem, social skills, and connectedness. Psychology in the Schools, 42, 65-77.

Karcher, M. J., \& Herrera, C. (2008). School-based mentoring. Research in Action, 6. (ERIC Document Reproduction Service No. ED502227).

Karcher, M. J., Kuperminc, G. P., Portwood, S. G., Sipe, C. L., \& Taylor, A. S. (2006). Mentoring programs: A framework to inform program development, research, and evaluation. Journal of Community Psychology, 34(6), 709-725.

Keller, T. E., \& Pryce, J. M. (2010). Mutual but unequal: Mentoring as a hybrid of familiar relationship roles. New directions for youth development, 2010(126), 33-50.

Kohnert, K. (2013). One insider's reflections on white privilege, race and their professional relevance. SIG 14 Perspectives on Communication Disorders and Sciences in Culturally and Linguistically Diverse (CLD) Populations, 20(2), 41-48. 
Kochan, F., Searby, L., George, M. P., \& Edge, J. M. (2015). Cultural influences in mentoring endeavors: Applying the cultural framework analysis process. International Journal of Mentoring and Coaching in Education, 4(2), $86-$ 106.

Lent, R. W., Hackett, G., \& Brown, S. D. (1999). A social cognitive view of school- to- work transition. The Career Development Quarterly, 47(4), 297-311.

Morgan, D. L. (1997). Focus Groups as Qualitative Research (2nd ed.). Thousand Oaks, CA: Sage.

Phinney, J. S., Dennis, J. M., \& Chuateco, L. I. (2005). The role of motivation, parental support, and peer support in the academic success of ethnic minority first-generation college students. Journal of College Student Development, 46(3), 223-236.

Plaut, V. C., Thomas, K. M., \& Goren, M. J. (2009). Is multiculturalism or color blindness better for minorities?. Psychological Science, 20(4), 444-446.

Plaut, V. C. (2010). Diversity science: Who needs it? Psychological Inquiry, 21(2), $168-174$.

Provalis Research. (2011). QDA Miner 4.0. User's guide. Montreal, QC, Canada.

Randolph, K. A., \& Johnson, J. L. (2008). School-based mentoring programs: A review of the research. Children \& Schools, 30(3), 177-185.

Rentschler, G. J., \& Gasior, R. M. (2011). Student Peer Mentoring: A tool for clinical educators. SIG 10 Perspectives on Issues in Higher Education, 14(1), 29-35.

Rhodes, J. E., \& DuBois, D. L. (2008). Mentoring relationships and programs for youth. Current Directions in Psychological Science, 17(4), 254-258.

Saenz, T. I. (2000). Issues in recruitment and retention of graduate students. Communication Disorders Quarterly, 21(4), 246-250.

Saenz, T. I., Wyatt, T. A., \& Reinard, J. C. (1998). Increasing the recruitment and retention of historically underrepresented minority students in higher education: A case study. American Journal of Speech-Language Pathology, 7(3), 39-48.

Shelmerdine, S., \& Louw, J. (2008). Characteristics of mentoring relationships. Journal of child and adolescent mental health, 20(1), 21-32.

Solberg, V. S., \& Viliarreal, P. (1997). Examination of self-efficacy, social support, and stress as predictors of psychological and physical distress among Hispanic college students. Hispanic Journal of Behavioral Sciences, 19(2), $182-201$.

Spencer, R. (2006). Understanding the mentoring process between adolescents and adults. Youth \& Society, 37(3), 287-315. 
Spencer, R. (2007). "It's not what I expected" A qualitative study of youth mentoring relationship failures. Journal of Adolescent Research, 22(4), 331-354.

Stewart, S. R., \& Gonzalez, L. S. (2002). Serving a diverse population: The role of speech-language pathology professional preparation programs. Journal of Allied Health, 31(4), 204-216.

Strauss, A., \& Corbin, J. (1990). Basics of Qualitative Research: Grounded Theory Procedures and Techniques. Newbury Park, CA: Sage.

Sufrin, R. L. (2014). The role of multicultural competence, privilege, attributions, and team support in predicting positive youth mentor outcomes. (Masters Thesis, DePaul University). Retrieved from http://via.library.depaul.edu/csh_etd/69

Wright-Harp, W., Mayo, R., Martinez, S., Payne, J, \& Lemmon, R. (November, 2012). Addressing health disparities in minority populations with communication disorders. Miniseminar presented at the annual convention of the American Speech-Language-Hearing Association, Atlanta, GA.

Wright-Harp, W., \& Cole, P. A. (2008). A mentoring model for enhancing success in graduate education. Contemporary Issues in Communication Science and Disorders, 35, 4-16.

Wright-Harp, W., \& Muñoz, E. (2000). Preparing bilingual speech-language pathologists: The development of an innovative master's degree program. Teacher Education and Special Education: The Journal of the Teacher Education Division of the Council for Exceptional Children, 23(4), 290302.

Wong, S. T., Seago, J. A., Keane, D., \& Grumbach, K. (2008). College students' perceptions of their experiences: What do minority students think?. Journal of Nursing Education, 47(4), 190-195. 


\section{Appendix A}

\section{Mentor Interview Questions and Rubric}

\section{Mentor Interview Questions}

1. Tell me about your experience as a student in this department. What are some characteristics of the program that stand out to you? Why might new students be attracted to this program?

2. What are some community programs of which you have volunteered and what did you learn about yourself in this volunteer work?

3. Why are you interested in mentoring?

4. Describe a challenge or obstacle of which you had to communicate with others to overcome.

5. Tell me about a time that you might have felt awkward or uncomfortable with others? What did you do that helped you to feel a sense of "fitting in"?

6. Are you willing to set aside 2 hours weekly as a mentor and what might you gain from this experience?

7. Is there anything else you would like me to know about you?

8. What questions do you have for me?

\section{Mentor Candidate Interview Rubric \\ Rate each candidate on a scale of 0-5 with $0=$ not demonstrated and $5=$ exceeds expectation.}

\begin{tabular}{|l|l|}
\hline Personal Disposition and Quality & Rating \\
\hline $\begin{array}{l}\text { 1. Demonstrates expertise and passion for their discipline. } \\
\text { demonstrates respectful communication across settings. }\end{array}$ & \\
\hline 3. Articulates understanding of personal strengths and & \\
weaknesses. & \\
\hline $\begin{array}{l}\text { 4. Displays appropriate positive attitude and professional integrity. } \\
\text { 5. Demonstrates a strong commitment to the idea that all students }\end{array}$ & \\
\hline can learn. & \\
\hline
\end{tabular}




\begin{tabular}{|c|}
\hline $\begin{array}{l}\text { 7. Demonstrates evidence of fairness and equitable treatment of } \\
\text { others. }\end{array}$ \\
\hline $\begin{array}{l}\text { 8. Recognizes the importance of diversity in the field and respect } \\
\text { for cultural, individual, and role differences, including age, } \\
\text { gender, ethnicity, sexual orientation, physical ability/disability, } \\
\text { language, and socioeconomic status }\end{array}$ \\
\hline $\begin{array}{l}\text { 9. Articulates the willingness to learn more about oneself } \\
\text { personally and professionally. }\end{array}$ \\
\hline $\begin{array}{l}\text { 10. Describes personal resiliency and dedication to see endeavors } \\
\text { through to the end. }\end{array}$ \\
\hline
\end{tabular}




\section{Appendix B}

\section{Focus Group Guide: LEAD Mentors}

\section{Mid-Point and Final Program Interview Questions:}

1. To what degree do you think you know your mentee?

2. How well did you and your mentee mesh?

3. How did you motivate your mentee if she/he were discouraged?

4. How did you motivate yourself?

5. If there were barriers, what were they and how did you overcome them?

6. Were there times you wanted to provide negative feedback? What were they? Did you provide it and if so, how?

7. What were some topics that you covered when you talked? Why do you think these topics were discussed?

8. What resources did you supply to the group and/or your mentee that you believe were effective. How do you know they worked?

9. Do you believe that time with your mentee should be more structured or less structured? Why?

10 . What would you do differently as a $2^{\text {nd }}$ year mentor?

11. What do you believe was the best mode for communicating with your mentor and just what did you communicate through this mode?

12. When you think about your own interests and world and whether or not it matched your mentee, do you think you grew in your cultural knowledge? If so why? If not, why not?

13. What role did social media play in your relationship?

14. How about the blog? What other or future ideas come to mind?

15 . What could we have done as a team more effectively?

16. How much "coming to you" did your mentee do? Did they actively seek you out and if so, what prompted it?

17. Where do you see the future of LEAD going? What are some resources you need to move into this direction? 


\section{Appendix C}

\section{Themes associated with Year 1}

Mentor processes (mentor focus)

- Effectiveness

- I cannot wait to share my story with mentees and really show them what our profession is all about and what makes it special.

○ This week I helped her with her HIPPA quiz and made sure she is going to take the correct classes next semester.

- This will be something new getting to mentor someone in regards to my career path, audiology.

○ It's helpful to be a mentor.

- Teamwork

I think that as a group, we all discovered some things or opinions that were very different and new to us.

- I hope to make lifelong friendships that will help me as a support system and to share ideas.

- I feel that some of the mentors are not taking it as seriously as others and that bothers me, that some feel that their time is more valuable than mine. But I do feel that within this group good things will come from it and greatness will be achieved.

- Personal Growth

- I'm learning that I need to manage my time a little better but I also need to learn to do things or myself.

○ Like, are you helping someone and is what you're doing meaningful? Are you ultimately contributing to what the program is designed for?

$\circ$ While meeting with my mentee I forgot about my sadness and then I thought later how fulfilled mentoring is going to make my life.

○ In my private life, I would like to learn how to listen better and not just jump into "fixing things".

- I tend to talk about myself so I hope I didn't come off as selfcentered.

○ I'm looking forward to teaching her which in turn will help me build my confidence.

- Maybe this program will be the very thing to inspire and push me just that much further. To study more, harder, to be more positive, more professional.

Mentor processes (mentee focus)

- Professional Relationship Development 
- We're in this program because we like to help people.

- We're building relationships constantly.

- I wish I could have had somebody as an undergraduate who guided me.

- A good thing about our meeting was that we were able to advise our mentees on what classes to take and what classes you should and should not take together.

- I wanted to give them the skills and the knowledge to be able to be able to step into a graduate program

- We were able to be honest and help each other out with thigs that she needed. So it was very beneficial.

- Mine participated in one of the career days. She gave her perspective as a mentee in our program and how it helped her. So I know that was effective. Reaching out to other students and letting them know what we do and how our program helps.

- Facilitating Mentee Knowledge/Skills

- She works at an animal shelter, and I love all types of animals. We both think it would be great to do some community service there.

- I feel like my mentee also has a lot on her plate so it was cool I was able to plan a mini session, spring semester, and some summer for her.

- Tried to offer advice on note taking, courses to take, workload, and how to handle stress.

- I took my mentee to the library and showed her the sections that would be helpful.

- I made her a packet that outlined the requirements and everything that she had to do. I just downloaded it from ASHA and put it in a folder and had it for her.

- We had a tutoring group, the workshop for writing as well, and the career day. My mentee said those were helpful.

Cultural processes

- Awareness

○ Talking about race, mentoring, our influences...very inspiring and eye opening.

- My eyes have been opened today...to others.

- I want to assist in bridging the diversity gap, educate those unfamiliar with our career services, and encourage those wanting to pursue the career further.

- It is very different to be in a room full of people that I barely know, who all come from different walks of life.

- Common Ground 
- We're all so diverse, but have a common purpose and goal in participating in this mentor program.

- We are both from like backgrounds but different experiences.

- We are all so different yet various parts of our life can allow us to relate to others in different ways.

- Discussion and discomfort

○ The conversation was difficult to have but needed.

- Although some people are uncomfortable, at least we began a very crucial dialogue.

- We have tackled a very difficult and uncomfortable topic: race/cultural stereotypes.

- I felt uncomfortable when talking about race. 


\section{Appendix D}

\section{Themes associated with Year 2}

Mentor processes (mentor focus)

- Open to experience

- We were able to open our mind to other opinions and even we didn't agree necessarily we accepted them and respected them.

- I continue to strive for that openness and this program has really helped me move towards that.

- Personal Growth

- I am looking forward to not only to what I can do for her, but also what it is that she can help me with.

O I really like being part of this program-it's making me look at myself, how I relate to others, and how I feel about myself and the work I'm doing.

- Teamwork

- I really believe that the entire group has come together as a team.

$\circ$ We are all quite supportive of each other and spoke openly about many of the political issues affecting us today.

- These activities are bringing us all closer together and I feel as though we are all working to build each other up as well as our mentees.

O I think everyone's personality is uniquely suited to make this experience a great one for them and their mentees.

- Everyone should reach out and work together, regardless of what they have or do not have in common, because we do all have one thing in common: we want this career in speech-language pathology, and are all working very hard towards it!

Mentor processes (mentee focus)

- Open to relationship

- I believe with my experience and openness, my mentees will realize that I am there for them and not be shy.

$\circ$ I really like my girls and I liked that they were open with me.

- Being a mentor was something that I was going to take very seriously to begin with, but after meeting her, I realize that this is something far more important than I ever would have imagined.

- Goal setting

- My main goals for them will be to be there and answer any questions they may have. 
- I want to be a friend and someone that can hopefully make their experience at school a little less stressful because I have been there too.

- I now know that my goal is to get them involved in the profession and provide resources to help alleviate stress about graduate school.

- I think that's why it's important for me to really come up with meaningful activities that are going to interest my mentees and make a difference.

- Concern for Mentee Knowledge/Skills

- While I think that talking about the profession is a great way to learn about it, I also believe that it is helpful to observe some sessions.

- I am happy that she is taking advantage of the phonetics lab and she has been fairly consistent in going most Mondays.

- Both really NEED guidance through their journey, someone other than the advisors or professors.

- I have tried to fill them in on the workshops, and NSSLHA meetings and opportunities for community service hours that are available to them.

- I emailed her about some more opportunities for her (NSSLHA and university-wide activities) and she wrote back that the information was exactly what she needed, so I am glad that I could help her out.

- Professional and personal relationships

- I really hope this program can break down the wall of grad and undergrad student.

- I really think she just wants a friend, and I will definitely be her friend and listen.

- We discussed certain things about the undergrad and grad program, how to study for classes, what they would like to get out of this mentoring program, and more.

- But, what I can do is just be there as encouragement, not only as their mentor but as a friend as well.

- We had a small mentor-mentee hang out on Thursday. That was really nice to get to know everyone and just hang out in a non-school environment.

Cultural processes

- Openness

- We were able to open our mind to other opinions and even we didn't agree necessarily we accepted them and respected them.

- Even this seemingly simple difference in culture was a great learning experience for both of us. 
- Most of the group even expanded on their personal backgrounds, and times that they have been and have felt discriminated against.

- I really enjoyed just talking about these topics and I learned a lot about some of my classmates that I did not know before, and everything that was said was somehow eye opening in a way.

- I really enjoyed listening to my classmates because there are times that I would not think about something a certain way and they were able to explain or open my mind up to something I may have not thought about before.

- Being a mentor for minority students, and as a minority myself, it is crucial to be accepting of all cultures.

- Discussion and Growth

○ These topics weren't easy to talk about with others but our group is very accepting and understanding.

- I thought it was a great discussion because it kind of carries over some barriers we might come across with our mentees as well as our future co-workers or even clients.

- I know we strayed off topic quite a bit, but today's conversation was amazing. It was really nice to talk about all of these heavy topics from all of these amazing individuals from such diverse backgrounds.

- We all shared stories about stigmas associated with either our faith, culture, or values and how that made us feel.

- From the readings and discussions on our cultural awareness and responsiveness will really help me to reflect on my personal beliefs and will help me in my career field when working with other who come from a different background than I.

- Empathy

- It's true, we have to be able to relate to people who are in the same position as we are or once were.

- I say that because when I was working on my leveling courses, every time I tried to approach a graduate student to get a little more information on grad school, they seemed so closed off and unavailable.

- Since I've been where they are at and feeling like I have no direction or idea about what I'm trying to step into, I feel like I'm more than willing to help. 
Teaching and Learning in Communication Sciences \& Disorders, Vol. 1 [2017], Iss. 2, Art. 3

- I gave her some idea of my background and where I come from and also what I hope to help her with. She, in turn, told me the same.

- One was supposed to meet with me on Thursday but she didn't show up. I wasn't upset- she must be very busy! 